\title{
INFLUÊNCIA DA DIETA AMINOACÍDICA NA COMPOSIÇÃO DO LEITE: REVISÃO DE LITERATURA
}

\author{
VRISMAN, Dayane Priscila ${ }^{1}$ \\ DA SILVA, Marlon Richard Hilário ${ }^{2}$ \\ FACCO, Fabíola Secretti ${ }^{1}$ \\ STRUCHER, Felipe ${ }^{1}$ \\ COSTA, Fernando Corazza ${ }^{1}$
}

RESUMO: Com uma produção de 27,5 bilhões de litros por ano, o Brasil ocupa a sexta posição do "ranking" mundial em produção de leite; e o Paraná, com 3,6 milhões de litros de leite produzidos no ano de 2010, ocupa o terceiro lugar no "ranking" nacional. Devido a esses números expressivos, a nutrição é uma área da Medicina Veterinária que vem crescendo a cada ano e dessa forma trouxe melhorias para produção animal. Dentre as técnicas utilizadas para maximizar a produção e a qualidade do leite, destacam-se a introdução de aminoácidos protegidos à dieta. Esses são ditos protegidos pois passam pelo rúmen sem serem alterados pela ação das bactérias e, chegam ao intestino intactos. Posteriormente serão absorvidos e servirão de base para a formação de novas moléculas de proteína e gordura na glândula mamária. Os principais aminoácidos que devem ser suplementados são a lisina e metionina, pois são considerados limitantes para a produção de leite, principalmente no que se refere aos animais de alta produção. Essa suplementação resulta em aumento no percentual de gordura e proteína no leite, conforme estudo de alguns autores. Logo, torna-se benéfico a adição de aminoácidos protegidos na dieta dos animais, pois os produtores irão receber um valor maior pago pelo litro do seu leite produzido uma vez que isso vem ocorrendo principalmente em sistemas de pagamento em que remunera-se pelo aumento na quantidade de sólidos totais do leite. Portanto é viável econômica e produtivamente o uso de aminoácidos na dieta de bovinos leiteiros.

Palavras-chave: Aminoácidos essenciais. Lisina. Metionina. Protegida. Sólidos totais.

\section{INFLUENCE OF DIET AMINO ACID IN THE COMPOSITION OF MILK: LITERATURE REVIEW}

\begin{abstract}
SUMMARY: With a production of 27,5 billion of liters per year, Brazil occupies the sixth position in the global "ranking" of milk prodution; and Paraná state, with 3,5 million liters of milk produced in 2010, occupies the third place in the national "ranking". Due to these impressive numbers, nutrition is one area of veterinary medicine that has been increasing every year, to thereby optimize all this production by animals. Among the techniques used to maximize milk production and quality include the introduction of protected amino acids to the diet. These are said to pass through the rumen protected because without being altered by the action of bacteria and reach the intestine intact. Lattely they are absorbed and subsequently form the basis for the formation of new protein and fat molecules in the mammary gland. The majors amino acids must be supplemented in this way are lysine and methionine, because they are regarded as limiting for the production of milk, mainly in relation to high producing animals. Supplementation results in an increase of the percentage of fat and protein in milk, according to some authors studies. Thus it is beneficial to add protected amino acids in the diet, because producers will receive a higher value paid for a liter of milk produced. This is happening mainly in payment systems that pays by the increase in the amount of total solids on milk. It is therefore considered feasible economically and productively the use of amino acids in the diet of dairy cattle.
\end{abstract}

Keywords: Essential amino acids. Lysine. Methionine. Protected. Solids

\footnotetext{
${ }^{1}$ Dicentes da Universidade Estadual do Centro-Oeste, UNICENTRO/Guarapuava

${ }^{2}$ Professor Doutorando da Universidade Estadual do Centro-Oeste, UNICENTRO/Guarapuava.
} 


\section{INTRODUÇÃO}

Com uma produção de 27,5 bilhões de litros por ano, o Brasil ocupa a sexta posição do "ranking" mundial em produção de leite. No terceiro trimestre de 2012, a aquisição de leite pelas indústrias foi de 5,2 bilhões de litros, um aumento de 2,8\% em relação ao mesmo trimestre de 2011 (IBGE, 2012). Os principais estados que se destacam em produção no Brasil são: Minas Gerais, Rio Grande do Sul, Goiás, São Paulo, Paraná e Santa Catarina, os quais no ano de 2008 foram responsáveis por $81,7 \%$ do total produzido no Brasil. No ano de 2010, o estado do Paraná produziu aproximadamente 3,6 milhões de litros de leite, correspondendo a 11,7\% da produção brasileira, ocupando o terceiro lugar no "ranking" nacional de produção leiteira. Os estados que ocupam a primeira e segunda posição como maiores produtores brasileiros de leite são Minas Gerais e Rio Grande do Sul, respectivamente (MEZZADRI, 2012).

Segundo os dados do IBGE (2012) a cadeia produtiva do leite no estado do Paraná tem evoluído em vários parâmetros. A produção entre os anos de 2001 a 2010 teve um aumento significativo de $89 \%$, bem como no número de animais ordenhados, um aumento de $35 \%$. Também foi registrado um incremento de $41 \%$ no volume produzido por vaca/ano. Dessa forma, na década passada, houve um aumento da produtividade dos animais quanto à produção de leite. No estado do Paraná, os municípios que se destacam na produção leiteira são: Carambeí, Castro, Palmeira e Arapoti. Esses locais se destacam por possuírem um dos melhores rebanhos leiteiros do país, onde a produtividade média pode chegar a 3.500 litros/vaca/ano. Esses valores são ainda maiores em Castro, município considerado como "centro de referência" em bovinocultura de leite, podendo atingir produções superiores a 8.000 litros/vaca/ano, igualando-se aos maiores países produtores de leite (MEZZADRI, 2005).

O aumento na produção dos animais a cada ano leva a uma maior necessidade nutricional. Por isso nos últimos anos, a busca para melhorar a eficiência na pecuária leiteira brasileira determinou o desenvolvimento e aprimoramento de técnicas para aumentar a produção dos animais, bem como melhorar a qualidade físico-química e nutricional do leite, além de reduzir a incidência de distúrbios metabólicos (ZAFFALON, 2010).

A nutrição de vacas leiteiras é um ramo que tem recebido um maior enfoque nos últimos

anos, determinando os requerimentos em energia e proteína para os animais, além da porcentagem de proteína degradável e não degradável no rúmen, como também os requerimentos em aminoácidos. Dentre as técnicas utilizadas para melhorar a produção e a qualidade do leite destacam-se a alimentação, com a introdução de certos nutrientes à dieta, o que recentemente vem ocorrendo pela adição de aminoácidos (SANCANARI et al., 2001). 
Utilizando fontes de aminoácidos protegidos na dieta, estes chegarão até o intestino sem sofrerem alterações pelas bactérias no rúmen, sendo posteriormente absorvidos. Com isso obteremos um aumento na concentração de aminoácidos no plasma, bem como de nitrogênio, sendo este disponível para a glândula mamária para uma maior síntese de proteínas no leite (SANCANARI et al., 2001).

O objetivo dessa revisão bibliográfica é informar e esclarecer, vantagens e desvantagens, da adição de aminoácidos na dieta dos animais, ressaltando suas principais influências para a produção animal, e ainda qual a sua interferência na composição do leite.

\section{DESENVOLVIMENTO}

\subsection{Metabolismo da proteína}

Os alimentos consumidos pelos ruminantes são inicialmente expostos à fermentação ruminal antes da digestão gástrica e intestinal (JUNIOR et al., 2007). O processo de digestão das proteínas resulta na formação de aminoácidos, necessários para manutenção das funções vitais, além das funções reprodutivas, crescimento, desenvolvimento e lactação (WATTIAUX, 2013).

As proteínas podem ser formadas pela combinação de 21 (vinte e um) aminoácidos principais, sendo que aproximadamente 10 (dez) são considerados como essenciais. Estes devem constar na dieta dos animais, pois sua síntese não ocorre ou ocorre em pequenas quantidades, de maneira que as exigências metabólicas dos animais com um alto nível de produção sejam atendidas (NRC, 2001). O padrão dos aminoácidos essenciais absorvidos no intestino pode ser um determinante nas características de produção de leite nos animais em lactação (RULQUIN et al., 1993 ${ }^{\mathrm{a}}$ ), sendo que os aminoácidos arginina, histidina, isoleucina, leucina, lisina, metionina, fenilalanina, treonina, triptofano e valina são considerados com essenciais.

A proteína bruta $(\mathrm{PB})$ contida na dieta dos ruminantes é composta pela proteína degradável no rúmen (PDR) e pela proteína não degradável no rúmen (PNDR). A primeira é degrada devido à ação de enzimas que os micro-organismos presentes no rúmen secretam. Segundo Santos (2011), o resultado da degradação da PDR é a formação de peptídeos de cadeias menores, aminoácidos e amônia, que servirão para a síntese de proteína microbiana e multiplicação celular, conforme ilustrado na Figura 1. 
Figura 1. Metabolismo da proteína em bovinos de leite.

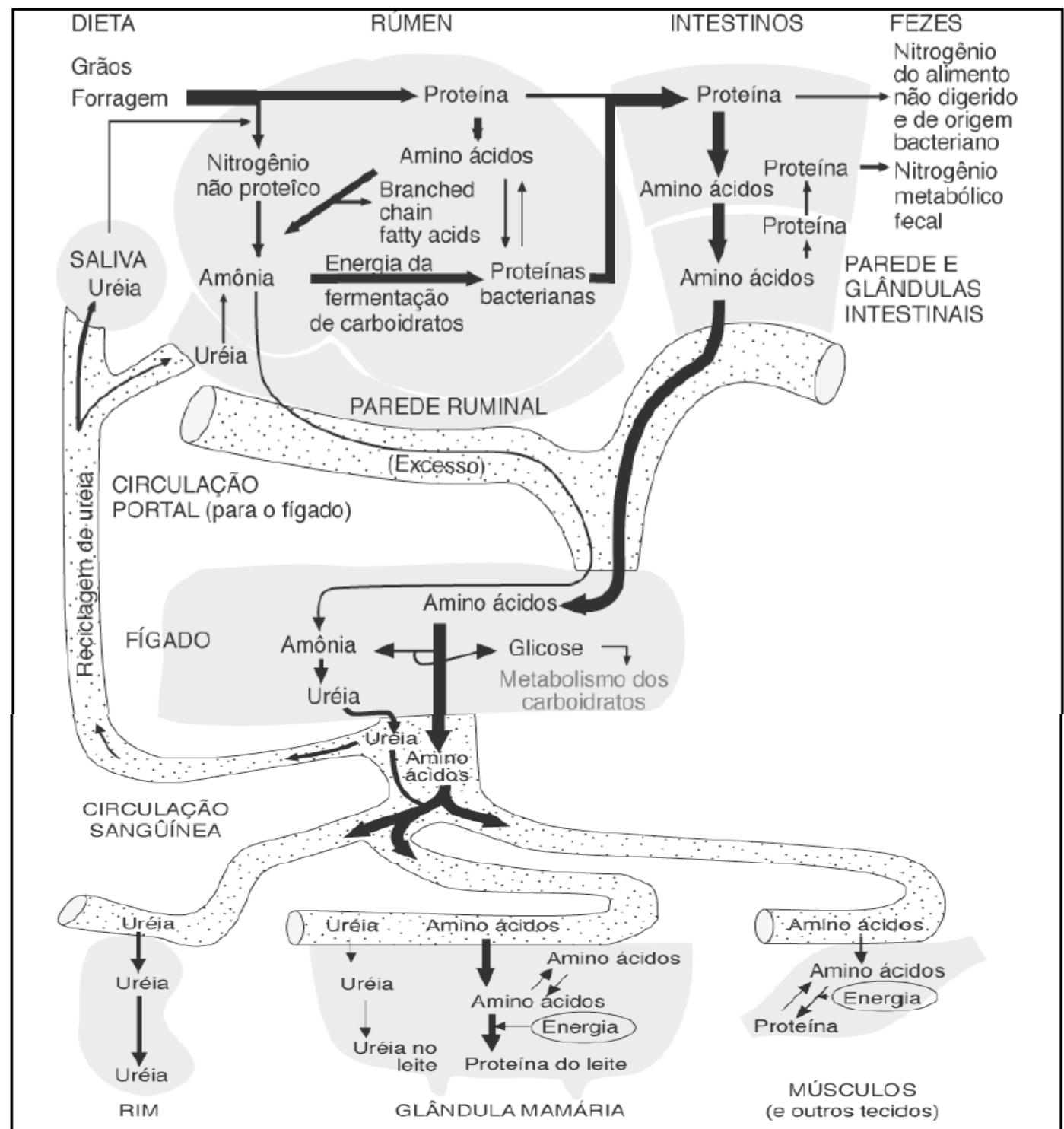

Fonte: WATTIAUX (2013).

A proteína microbiana resultante e a PNDR irão sofrer a digestão gástrica no abomaso, transformando essas moléculas em cadeias cada vez menores de proteínas até resultar na molécula de um único aminoácido. No intestino delgado essa molécula de aminoácido será absorvida pela mucosa e chegará na corrente sanguínea, atingindo o fígado. Nesse órgão uma parte desses aminoácidos poderá ser transformada em amônia e depois à ureia. Essa ureia resultante poderá retornar ao rúmen via saliva, poderá ser excreta pelos rins via urina e também poderá ser excretada no leite. Os aminoácidos que não foram transformados em amônia e ureia no fígado serão importante para a formação de proteínas, como proteínas musculares e também proteínas do leite (SANTOS, 2011).

A quantidade de PDR e PNDR que o animal irá aproveitar tem influência da ingestão de matéria seca. Quanto maior a ingestão de matéria seca, como o que ocorre em vacas de alta 
produção, maior será a taxa de passagem do alimento pelo rúmen, com isso a PDR do alimento diminui e a PNDR aumenta (ALVES, 2004). Porém, segundo Clark et al., (1992) o excesso de fonte proteica rica em PNDR na dieta, com a finalidade de aumentar a proteína que chega ao intestino e posterior absorção, pode trazer prejuízos, pois dessa forma diminui-se a produção de proteína microbiana, uma fonte de excelente qualidade em aminoácidos.

Em ruminantes, a exigência de aminoácidos a serem absorvidos pelo intestino para posterior síntese do leite é resultado da síntese de proteína microbiana no rúmen, da proteína não degradada no rúmen e da proteína endógena (JUNIOR et al., 2007), ou seja, proteína metabolizável que é disponível para o metabolismo animal (RIBEIRO, 2008). A proteína microbiana fornece $50 \%$ ou mais dos aminoácidos disponíveis para a absorção intestinal, considerada portanto como uma fonte de alta qualidade em aminoácidos, sendo o restante oriunda da proteína não degradada no rúmen (WATTIAUX, 2013). Para vacas de alta produção, somente a proteína microbiana sintetizada pelas bactérias do rúmen, pode ser insuficiente para atingir a grande demanda de aminoácidos pela glândula mamária (SANCANARI et al., 2001; WATTIAUX, 2013). Por isso é importante que a fonte de PNDR tenha uma composição em aminoácidos diferentes daqueles da proteína microbiana, para que dessa forma se complementem (GONÇALVES, 2009) e, supram as necessidades de aminoácidos dos animais de alta produção (WATTIAUX, 2013).

Quando se deseja aumentar os níveis de produção de leite dos animais, aumentam-se também as exigências proteicas. Para aliar essas duas condições, há a necessidade de aumentar a eficiência da síntese de proteína microbiana e, que parte da proteína da dieta seja composta pela proteína não degradável no rúmen (ALVES, 2004). Segundo Swanepoel et al., (2010) para aumentar a produção de leite dos animais é importante que estes aumentem o consumo de proteína na dieta. Também é importante suplementar os aminoácidos, para dessa maneira atender as exigências em produção de leite bem como a síntese de proteína.

Por tanto umas das formas de melhorar a produção, tanto em quantidade como em qualidade, do leite das vacas de alta produção seria através de uma suplementação na dieta com aminoácidos essenciais na forma protegida. Um dos principais aminoácidos considerado como limitante para a produção leiteira é a metionina, sendo necessária a sua adição na dieta na forma protegida da degradação ruminal, para dessa forma aumentar o índice produtivo dos animais (SANCANARI et al., 2001).

Após serem absorvidos no intestino, os aminoácidos são carreados até a glândula mamária pela circulação sanguínea e, nesse compartimento poderão ser transformados em outras moléculas, ou poderão ser oxidados para a síntese de energia, sendo que a grande maioria é 
utilizada para a síntese de novas moléculas de proteína, as quais serão excretadas no leite posteriormente (WATTIAUX, 2013).

\section{Dieta aminoacídica e alteração na composição do leite}

Aminoácidos na forma livre não são recomendados na suplementação de uma dieta para ruminantes, pois essas moléculas são rapidamente degradadas no rúmen. Então, para Kung e Rode (1996), uma alteração química ou uma proteção física deve ser instituída para proteger esses aminoácidos da degradação ruminal e, dessa forma aumentar a disponibilidade desses no intestino.

As exigências de aminoácidos pelos bovinos podem ser atendidas de duas formas: pelo balanceamento de aminoácidos presente nos alimentos e pela utilização de aminoácidos protegidos como mencionados anteriormente. Segundo Gabilan (2013), as principais fontes utilizadas para o balanceamento proteico na dieta dos animais são o farelo de soja e o farelo de algodão. Porém, esses alimentos são ricos em lisina e possuem baixos teores de metionina, devendo este ser suplementado caso a dieta não atinja níveis adequados. Segundo Alves (2004), as principais formas de se proteger os aminoácidos realizados pela indústria são: produção de aminoácidos análogos (Metionina hidroxi-análoga; Hidroximetil DL-metionina cálcica; Monoplus di-N-Hidroximetil-L-Lisina cálcica); recobrimento com gordura, ou seja, misturas de gorduras e proteínas, proteínas tratadas com formaldeído, ou sabões cálcicos de ácidos graxos de cadeia longa; e encapsulamento com compostos poliméricos resistentes a degradação ruminal, mas que são hidrolisados no abomaso. Os produtos mais utilizados comercialmente para realizar essa suplementação são: Mepron ${ }^{\circledR}$ M85 e Smartamine ${ }^{\circledR}$ M.

Uma ração enriquecida com aminoácidos limitantes, principalmente a lisina e a metionina, podem ajudar a aumentar a síntese de proteína no leite, assim como aumentar a absorção desses e outros aminoácidos. Desse modo, tem-se indicada a suplementação desses elementos (ZAFFALON, 2010).

Segundo experimento realizado por Lara et al., (2006) concluíram que a suplementação com metionina protegida é importante na dieta de vacas com uma produção leiteira acima de 35 $\mathrm{kg} /$ dia. Uma ótima resposta de aumento, tanto na produção leiteira como no percentual de proteína no leite, foi obtida com uma inclusão de $16 \mathrm{~g} / \mathrm{vaca} / \mathrm{dia}$ de metionina. Já para Chalupa e Sniffen (1991), as melhores respostas foram obtidas quando a suplementação foi feita com 16 30 g/dia de lisina e 10 - 15 g/dia de metionina. Para Schwab (1996), a porcentagem de lisina e metionina que chega ao intestino para ser absorvido devem ser de $15 \%$ e $5 \%$ (relação de 3:1) respectivamente, em relação ao total de aminoácidos essenciais, para dessa maneira maximizar a 
produção e o teor de proteína no leite. Já em pesquisa realizada por Rulquin e Verité (1993), foi constatado que a porcentagem dos aminoácidos lisina e metionina precisam ser de 7,3\% e 2,5\%, respectivamente, em relação aos aminoácidos metabolizados na dieta das vacas em lactação, para otimizar a produção de leite e de proteína. Segundo Sniffen et al., (2001) dietas que contenham menos do que 2,10 - 2,20\% de metionina e 6,0 - 6,5\% de lisina reduzem o percentual de proteína no leite. $\mathrm{O}$ balanceamento de lisina e metionina na dieta geralmente resultam em um aumento de proteína do leite em 0,1 a $0,2 \%$ e aumento na produção de leite em até $4 \%$ no início da lactação (SLOAN et al., 1998).

Segundo estudo realizado por Rulquin e Verité (1993), a suplementação com aminoácidos na dieta dos animais proporcionou acréscimo na produção de leite $(+0,1 \mathrm{~kg} / \mathrm{dia})$, nos teores de gordura $(+0,1 \mathrm{~g} / \mathrm{kg})$ e proteína $(+0,9 \mathrm{~g} / \mathrm{dia})$. Uma maior resposta ocorreu quando: lisina e metionina foram suplementadas em conjunto na dieta e, as rações foram à base de milho com alto teor de proteína. Em outro estudo realizado por Robinson (1996), uma suplementação na dieta dos animais com metionina e lisina protegida da degradação ruminal resultou em um aumento na produção de leite, assim como, na gordura, proteína e lactose do leite. Segundo Schwab (1996 ${ }^{\mathrm{a}}$, o aumento no teor e rendimento de proteína do leite pela suplementação de lisina e metionina são maiores quando a ingestão de PNDR é alta, quando as vacas estão no início da lactação e quando as vacas são de alta produção, porém essa variação na composição do leite é totalmente dependente do nível de proteína na dieta, requerimento dos animais e dos ingredientes utilizados na composição da dieta.

Consta na Tabela 1 os resultados obtidos por inúmeros pesquisadores quanto ao uso de metionina e lisina na dieta de vacas leiteiras. Segundo Suksombat et al., (2011) a adição de 22 g/vaca/dia de HMTBa (um análogo sintético da metionina) resultou nas seguintes alterações: aumento de $1,9 \mathrm{~kg} /$ dia na produção de leite, aumento de $51 \mathrm{~g} /$ dia de proteína do leite (porém em menor percentual devido ao efeito diluição: $-0,03 \%$ ), bem como $55 \mathrm{~g} / \mathrm{dia}$ de aumento na gordura do leite $(-0,08 \%)$. Em experimento realizado por Cermáková et al., (2012) a adição de 19 g/vaca/dia de Smartamine ${ }^{\circledR}$ resultou em: aumento na produção leiteira dos animais em 0,37 $\mathrm{kg} / \mathrm{dia}$, aumento de $30 \mathrm{~g} /$ dia de proteína $(0,08 \%)$ e uma diminuição no percentual de gordura em $0,05 \%$, porém sem alterações na sua quantidade produzida por dia quanto aos tratamentos. 
Tabela 1 - Variação na composição do leite pela inclusão de aminoácidos protegidos na dieta dos animais, conforme resultado de alguns autores.

\begin{tabular}{|c|c|c|c|c|c|c|}
\hline $\begin{array}{l}\text { Nível de } \\
\text { inclusão }\end{array}$ & $\begin{array}{l}\text { Produção } \\
\text { de leite } \\
\text { (kg/dia) }\end{array}$ & $\begin{array}{l}\text { Produção } \\
\text { de } \\
\text { proteína } \\
\text { (g/dia) }\end{array}$ & $\begin{array}{c}\text { Produção } \\
\text { de gordura } \\
\text { (g/dia) }\end{array}$ & $\begin{array}{c}\text { Proteína } \\
(\%)\end{array}$ & $\begin{array}{c}\text { Gordura } \\
(\%)\end{array}$ & Autores \\
\hline 22 g/dia HMTBa & $+1,9$ & +51 & +55 & $-0,03$ & $-0,08$ & $\begin{array}{c}\text { Suksombat et al. } \\
2011\end{array}$ \\
\hline $\begin{array}{c}19 \mathrm{~g} / \text { dia } \\
\text { Smartamine }^{\circledR} \\
\end{array}$ & $+0,37$ & +30 & 0 & 0,08 & $-0,05$ & $\begin{array}{c}\text { Cermáková et al. } \\
2012 \\
\end{array}$ \\
\hline $\begin{array}{l}42 \mathrm{~g} / \mathrm{dia} \text { DL- } \\
\text { Metionina }\end{array}$ & $+2,6$ & - & - & 0,26 & 0,47 & Yang et al. 2010 \\
\hline $\begin{array}{c}16 \mathrm{~g} / \mathrm{dia} \\
\text { Mepron }{ }^{\circledR} \mathrm{M} 85\end{array}$ & $+4,4$ & +158 & +67 & 0,14 & $-0,02$ & Lara et al. 2006 \\
\hline $\begin{array}{c}8,4 \mathrm{~g} / \mathrm{dia} \\
\text { metionina } \\
\text { protegida }\end{array}$ & -0.61 & -10 & +130 & 0,02 & 0,50 & $\begin{array}{c}\text { Sancanari et al. } \\
2001\end{array}$ \\
\hline $\begin{array}{l}41 \mathrm{~g} / \text { dia lisina } \\
\text { protegida }\end{array}$ & $-0,9$ & -20 & -130 & - & - & $\begin{array}{c}\text { Swanepoel et al. } \\
2010\end{array}$ \\
\hline $\begin{array}{l}41 \mathrm{~g} / \text { dia lisina } \\
\text { protegida* }\end{array}$ & $+0,82$ & +20 & +120 & - & - & $\begin{array}{c}\text { Robinson et al. } \\
2011\end{array}$ \\
\hline $\begin{array}{l}41 \mathrm{~g} / \text { dia lisina } \\
\text { protegida } * *\end{array}$ & $+2,03$ & +80 & +100 & - & - & $\begin{array}{l}\text { Robinson et al. } \\
2011\end{array}$ \\
\hline $\begin{array}{l}83,7 \mathrm{~g} / \mathrm{dia} \\
\text { metionina }\end{array}$ & $+0,6$ & +62 & +17 & 0,10 & $-0,06$ & Leonardi et al. 2003 \\
\hline $\begin{array}{l}63,3 \mathrm{~g} / \mathrm{dia} \\
\text { metionina }\end{array}$ & $-1,7$ & -31 & +9 & 0,07 & 0,12 & Leonardi et al. 2003 \\
\hline
\end{tabular}

* vacas em terço médio de lactação

** vacas em início de lactação

Yang et al., (2010) suplementando os animais com $42 \mathrm{~g} / \mathrm{dia}$ de DL-metionina obteve aumento de 2,6 kg leite/dia, aumento em $0,26 \%$ de proteína e $0,47 \%$ de gordura. Lara et al., (2006) adicionou $16 \mathrm{~g} / \mathrm{dia}$ de Mepron ${ }^{\circledR}$ M85 na dieta dos animais, o que resultou em: aumento de 4,4 kg/dia de leite, $158 \mathrm{~g} /$ dia de proteína $(0,14 \%)$ e $67 \mathrm{~g} /$ dia de gordura no leite $(-0,02 \%)$. Segundo esse autor o aumento na proteína do leite foi devido a maior produção de caseína por esses animais e, por uma diminuição nos níveis de ureia circulante (Tabela 1).

Sancanari et al., (2001) realizou o seu experimento suplementando a dieta dos animais com 8,4 g/dia de metionina protegida, porém em seu resultado obteve uma menor produção de leite pelos animais (-0,61 kg/dia), bem como de proteína (-10 g/dia) e um aumento na produção de gordura (130 g/dia), conforme Tabela 1. Em seu experimento Sancanari et al., (2001) utilizou vacas primíparas e multíparas e, mesmo apesar da diminuição na produção dos componentes anteriormente citados em relação ao tratamento controle, chegou à conclusão que em vacas multíparas a adição de metionina prolongou a curva de lactação e, nas vacas primíparas houve uma maior produção de leite. Atribuiu a diminuição da quantidade de proteína devido ao momento em que foram obtidas as amostras de leite para análise, próximo ao pico de lactação, 
onde o teor de proteína atinge valores mínimos; e também pelas primíparas estarem em desenvolvimento e a metionina ter sido utilizada para outras funções físiológicas, como crescimento dos animais, desenvolvimento do úbere e formação de células secretoras de leite. Os baixos teores de gordura em seu trabalho ocorreram provavelmente porque os animais estavam na fase inicial de lactação, época em que a produção de gordura é inversamente proporcional à produção de leite.

Ainda conforme Tabela 1 Leonardi et al., (2003), utilizando dois níveis de suplementação de metionina aos animais obteve, na inclusão de 83,7 g/dia um aumento de 0,6 kg leite/dia, aumento na proteína (62 g/dia) e gordura (17 g/dia); já na inclusão de 63,3 g/dia de metionina diminuiu a produção de leite em $1,7 \mathrm{~kg} /$ dia dos animais, assim como a proteína $(-31 \mathrm{~g} / \mathrm{dia})$, porém aumentou o teor de gordura ( $9 \mathrm{~g} / \mathrm{dia})$. O aumento nos teores de gordura no leite em uma dieta com aminoácidos protegidos é devido ao aumento na concentração plasmática de ácidos graxos não esterificados, permitindo dessa forma que mais ácidos graxos sejam extraídos pela glândula mamária e incorporados à gordura do leite, consequentemente aumentando os seus valores. Embora esse aumento seja dependente de outros fatores, como nível de proteína da dieta, exigências dos animais e alimentos utilizados na alimentação, uma maior elevação nos teores de gordura no leite ocorre quando os animais são alimentados com dietas onde a fonte proteica é constituída com produtos a base de soja (SANCANARI et al., 2001).

Quando levamos em consideração a adição de somente lisina na dieta dos animais, temos como resultado da pesquisa realizada por Swanepoel (2010), em que adicionou $41 \mathrm{~g}$ de lisina protegida/vaca/dia e obteve uma redução na produção de leite $(41,8 \mathrm{~kg}$ de leite/dia quando não adicionado lisina versus 40,9 kg/dia quando adicionado), bem como nos teores de proteína no leite (1,27 versus 1,25 kg/dia). Para Pierpenbrink et al., (1996), essa redução na produção de leite pela adição de lisina protegida da degradação ruminal sem metionina, pode ser causada pelos efeitos prejudiciais de quantidades excessivas e/ou quantidades inadequadas de lisina adicionada na dieta dos animais. Já em experimento realizado por Robinson et al., (2011) em que incluiu na dieta dos animais lisina protegida na mesma quantidade do experimento realizado por Swanepoel (41 g/vaca/dia), obteve resultados diferentes, os quais foram: aumento na produção de leite (50 versus $48 \mathrm{~kg} / \mathrm{dia})$, gordura (1,82 versus $1,72 \mathrm{~kg} / \mathrm{dia})$, lactose (2,36 versus 2,24 $\mathrm{kg} / \mathrm{dia})$ e concentração de proteína (28,8 versus $28,2 \mathrm{~g} / \mathrm{kg}$ ) nos animais em início de lactação. Para este autor houve uma maior absorção de lisina no intestino, onde este facilitou a absorção de outros aminoácidos, aumentando dessa maneira, tanto a produção de leite como os teores de gordura e proteína.

Para Fonseca et al., (2013) a suplementação com aminoácidos na dieta dos animais, pode não resultar em um aumento significativo na produção média de leite, mas em aumento nos 
teores de gordura. Isso traz um grande resultado de ordem econômica, no qual o leite é pago ao produtor por qualidade e não por quantidade.

Dieta para os ruminantes que apresentem qualquer deficiência em um dos aminoácidos essenciais resultará em um menor desempenho produtivo, embora esse decréscimo varie conforme qual aminoácido não está balanceado na dieta dos animais (ROBINSON et al., 1999).

\section{Mensuração do nitrogênio uréico no leite e avaliação do balanço entre PDR e PNDR}

Devido à nutrição ser a parte mais onerosa em uma propriedade de pecuária leiteira, é importante que esta esteja suprindo todas as exigências dos animais, que o balanceamento nutricional esteja correto para cada categoria. É importante que o dinheiro seja bem empregado pelo produtor, para que retorne na forma de um melhor desempenho produtivo animal.

Segundo Peres (2001) o monitoramento em qualquer atividade é uma ferramenta que permite a identificação de "pontos chaves", bem como "entraves" em uma cadeia produtiva e, modificações feitas nos procedimentos padrões poderão ser visualizadas e acompanhadas por esse monitoramento.

Uma forma de monitorar a nutrição do rebanho é através da composição do leite dos animais, embora seja uma ferramenta ainda pouco explorada pelo produtor.

Um teste que pode ser utilizado para monitorar a nutrição dos animais é através da mensuração do nitrogênio uréico no leite. Este componente representa a porção de nitrogênio no leite na forma de ureia. Ela estará presente no leite devido a um excesso de proteína na dieta, principalmente da forma degradável no rúmen. O excesso dessa fração será absorvido pela parede ruminal na forma de amônia e transportada para a corrente sanguínea, pois os micro-organismos do rúmen, devido ao excesso, não conseguem transformar a proteína da dieta em proteína microbiana. Na corrente sanguínea, essas moléculas passam pelo fígado onde serão biotransformadas em ureia. Por ser uma molécula com alta permeabilidade, ela passa por difusão para o leite, sendo excretado juntamente com o mesmo (PERES, 2001).

Como o excesso de proteína da dieta é excretada no leite na forma de ureia (além de estar presente na urina e fezes), o produtor pode utilizar um teste para determinar se a dieta que está fornecendo aos seus animais está balanceada para proteína. Esse teste é através da determinação do nitrogênio uréico do leite. Resultados abaixo de $12 \mathrm{mg} / \mathrm{dl}$ de ureia no leite indicam deficiência proteica, o que pode estar limitando a produção de proteína microbiana e desempenho animal. Por outro lado, valores acima de $18 \mathrm{mg} / \mathrm{dl}$ indicam que estão ocorrendo perdas, sejam perdas energéticas para eliminar essa ureia, sejam perdas de proteínas da dieta que estão em excesso, ou as frações de PDR e PNDR não estão balanceadas (PERES, 2001). 
Com a determinação desse parâmetro no leite obtemos informações importantes a respeito do balanço proteico nos animais. Dessa forma é importante a sua mensuração, para não ocasionar prejuízos aos produtores, devido ao fornecimento inadequado de proteína, a fração mais onerosa dentro de uma dieta para os ruminantes (PESSOA et al., 2009).

\section{CONCLUSÃO}

Devido as transformações recorrentes no sistema de pagamento do leite, com valorização para o leite de melhor qualidade (produto com maior quantidade de sólidos totais), há um maior interesse pelos produtores em otimizar essa produção. Os mesmos devem controlar para que os valores de referência não estejam muito acima do permitido, pois o excesso também poderá levar a penalizações, incluindo um menor valor pago pelo litro do leite.

A porcentagem de proteína no leite pode variar conforme a genética do animal, o estágio de lactação, estação do ano e a quantidade de proteína presente na dieta. Isso não significa que não devemos suplementar a nutrição desses animais e que não devemos nos preocupar com o balanceamento adequado dos aminoácidos essenciais. Pelo contrário, é importante realizar essa prática principalmente em vacas de alta produção, para aperfeiçoar a produção no que se refere à porcentagem de gordura e proteína no leite, objetivos da adição dos aminoácidos limitantes na dieta.

Portanto, a suplementação dos animais de alta produção com aminoácidos protegidos da degradação ruminal, principalmente lisina e metionina, tem a finalidade de preservar esses compostos até atingirem o intestino, sem sofrerem grandes modificações e sofrerem alterações pelas bactérias do rúmen. Dessa forma serão absorvidos e posteriormente servirão de base para a formação de novas moléculas de proteína e gordura na glândula mamária.

\section{REFERÊNCIAS}

ALVES, D.D. Nutrição aminoacídica de bovinos. Revista Brasileira de Agrociência, v.10, n.3, p.265-271, 2004.

CERMÁKOVÁ, J.et al. Effects of a rúmen-protected formo f methionine and a methionine analogue on the lactation performance of dairy cows. Czech Journal of Animal Science, v.57, n.9, p.410-419, 2012.

CHALUPA, W.; SNIFFEN, C.J. Protein and amino acid nutrition of lactating dairy cattle in dairy nutrition management. Veterinary Clinics of North America, v.7, n.2, p.353-372, 1991. 
CLARK, J.C.; KLUSMEYER, T.H.; CAMERON, M.R. Microbial protein synthesis and flows of nitrogen fractions to the duodenum of dairy cows. Journal of Dairy Science, v.75, n.8, p.23042323, 1992.

FONSECA, L.M.et al. Situação da qualidade do leite cru em Minas. Disponível em:< http://www.terraviva.com.br/clique/cbqlvfinalCBQL.pdf > Acesso em: 20 abr. 2013.

GABILAN, J. Suplementação de aminoácidos para Bovinos de Leite. Disponível em: <http://www.racoescomigo.com.br/noticias/suplemento.pdf $>$. Acesso em: 24 abr. 2013.

GONÇALVES, L.C.; BORGES, I.; FERREEIRA, P.D.S. Alimentação de gado de leite. Belo Horizonte: FEPMVZ, p.128-178, 2009.

IBGE. Intituto Brasileiro de Geografia e Estatística. Estatística da Produção Pecuária 2012. Disponível em: < http://www.ibge.gov.br/home/estatistica/indicadores/agropecuaria/producaoagropecuaria/abateleite-couro-ovos_201202_publ_completa.pdf >. Acesso em: 03 maio 2013.

JUNIOR, P.R.; SAMPAIO, A.A.M.; VIEIRA, P.F. Disponibilidade e absorção de aminoácidos em bovinos alimentados com diferentes fontes de compostos nitrogenados. Revista Brasileira de Zootecnia, v.36, n.4, p.960-967, 2007.

KUNG, L.; RODE, L.M. Amino acid metabolism in ruminants. Animal Feed Science Technology, 59, p.167-172, 1996.

LARA,A.et al. Milk production in Holstein cows supplemented with different levels of ruminally protected methionine. Livestock Science, 105, p.105-108, 2006.

LEONARDI, C.; STEVENSON, M.; ARMENTANO, L.E. Effect of two levels of crude protein and methionine supplementation on performance of dairy cows. Journal of Dairy Science, p.4033-4042, 2003.

MEZZADRI,F. Panorama da Pecuária Leiteira: Aspectos internacionais, nacionais estaduais. Curitiba: Secretaria de Estado da Agricultara e Abastecimento, 2005.

MEZZADRI, F. Análise da conjuntura agropecuária, ano 2011/12. Curitiba: Secretaria de Estado da Agricultara e Abastecimento, maio 2012.

NRC - NATIONAL RESEARCH COUNCIL. Nutrient requirements of dairy cattle. Washington: National Academic Press, 7. ed, 2001. p.381.

PERES, J.R. O leite como ferramenta do monitoramento nutricional. In: GONZÁLEZ, F.H.D.; DÜRR, J.W.; FONTANELI, R.S. Uso do leite para monitorar a nutrição e o metabolismo de vacas leiteiras. Porto Alegre: UFRG, 2001.

PESSOA, R.A.S.et al. Balanço de compostos nitrogenados e produção de proteína microbiana em novilhas leiteiras alimentadas com palma forrageira, bagaço de cana-de-açúcar e ureia associados a diferentes suplementos. Revista Brasileira de Zootecnia, v.38, n.5, p.941-947, 2009.

PIEPENBRINK, M.S.; OVERTON, T.R.; CLARK, J.H. Response of cows fed a low crude protein diet to ruminally protected methionine and lysine. Journal of Dairy Science, p.16381646, 1996. 
RIBEIRO, C.B. Proteína: avaliação de alimentos e exigência em ruminantes. Programa de Pós Graduação em Ciência Animal da Universidade Federal do Mato Grosso do Sul, 2008.

ROBINSON, P.H. Rumen protected amino acids for dairy cattle: What is the future? Animal Feed Science and Technology, p.81-86, 1996.

ROBINSON, P.H.et al. Influence of Postruminal supplementation of methionine and lysine, isoleucine, or all three amino acids on intake and chewing behavior, ruminal fermentation, and milk and milk component production. Journal of Animal Science, p.2781-2792, 1999.

ROBINSON, P.H.et al. Productive responses of lactating dairy cattle to supplementing high levels of ruminally protected lysine using a rumen protection technology. Animal Feed Science and Technology, 168, p.30-41, 2011.

RULQUIN, H.; VERITÉ, R. Amino acid nutrition of dairy cows: productive effects and animal requirements. In: GARNSWORTHY, P.C.; COLE, D.J.A. Recent advances in animal nutrition. Nittingham: University Press, p.55-77, 1993.

RULQUIN, H.et al. Milk production and composition as a function of postruminal lysine and methionine supply: a nutrient-responde approach. Livestock Production Science, p.69-90, $1993^{\mathrm{a}}$.

SANCANARI, J.B.D.et al. Efeito da metionina protegida e não protegida da degradação ruminal sobre a produção e composição do leite de vacas holandesas. Revista Brasileira de Zootecnia, v. 30, n.1, p.286-294, 2001.

SANTOS, F.A.P. Metabolismo de proteínas. In: BERCHIELLI, T.T.; PIRES, A.V.; OLIVEIRA, S.G. Nutrição de ruminantes. 2.ed. Jaboticabal: Funep, 2011. p.255-285.

SCHWAB, C.G. Rumen-protected amino acids for dairy cattle: progress towards determining lysine and methionine requirements. Animal Feeding Science Technology, v.59, p.87-101, $1996^{\mathrm{a}}$.

SCHWAB, C.G. Amino acid nutricion of the dairy cow: current status. In: CORNELL NUTRICION CONFERENCE FOR FEED MANUFACTURERS. Proceedings... Ithaca: Cornell University, p.184-198, 1996.

SLOAN, B.K.; GARTHWAITE, B.D.; SCHWAB, C.G. Pratical formulation of dairy cow diets for digestible amino acids to improve nitrogen efficiency ant the bottom line. In: CORNELL NUTRITION CONFERENCE FOR FEED MANUFACTURERS. Proceedings... Ithaca: Cornell University, p.51-61, 1998.

SNIFFEN, C.J.et al. Amino acid nutrition of the lactating cow. In: CORNELL NUTRICION CONFERENCE FOR FEED MANUFACTURERS. Proceedings... Rochester, NY. Cornell University, Ithaca, NY, p. 188-197, 2001.

SUKSOMBAT, W. et al. Effects of Met Hydroxy Analog plus MINTREX ${ }^{\circledR}$ Dairy Supplementation on Performance of Lactating Dairy Cows. Journal of Animal and Veterinary Advances, v.10, n.21, p.2814-2818, 2011. 
SWANEPOEL, N.; ROBINSON, P.H.; ERASMUS, L.J. Amino acid needs of lactating dairy cows: Impacto $\mathrm{f}$ feeding lysine in a ruminally protected form on productivity of lactating dairy cows. Animal Feed Science and Technology, p.79-94, 2010.

WATTIAUX, M.A. Essenciais em gado de leite: metabolismo de proteína em bovinos de leite. Wisconsin-Madison: Instituto Babcock para Pesquisa e Desenvolvimento da Pecuária Leiteira Internacional. Disponível em: < http://babcock.wisc.edu/sites/default/files/de/pt/de_05.pt.pdf > . Acesso em 22 abr. 2013.

YANG, W.R.; SUN, H.et al. Effects of rumen-protected methionine on dairy performance and amino acid metabolism in lactating cows. American Journal of Animal and Veterinary Sciences, v.5, n.1, p.1-7, 2010.

ZAFFALON, F.T. Efeito da suplementação parenteral com aminoácidos e vitaminas na produção e composição mineral do leite de vacas da raça holandesa. 2010. Dissertação (Mestrado em Produção Animal) Universidade Camilo Castelo Branco. Descalvado. 